\title{
A deficiência como expressão da diferença
}

Disability as an expression of difference

Luciene Maria da Silva ${ }^{1}$

\section{Resumo}

Este trabalho destaca o debate sobre as diferenças que dá fundamento às propostas inclusivistas na contemporaneidade. Tomamos como referenciais fundamentais estudos que não consideram ser a deficiência uma condição estática, natural e definitiva, posto que ela está inscrita nas relações e interações que determinam seu entendimento na sociedade. É, portanto, uma diferença que emerge no processo de produção da existência dos povos, em locais e momentos históricos distintos, assim como são, nesse sentido, as diferenças étnicas, os códigos lingüísticos ou as crenças religiosas. Em síntese, a diferenciação e individuação que dão substância à emancipação humana ainda são promessas, pois o indivíduo que se diferencia é um outro negado socialmente, freqüentemente perseguido para ser moldado, incluído e adaptado.

Palavras-chave: Diferença; Preconceito; Deficiência

\section{Abstract}

This work emphasizes the debate about differences which gives support to the inclusive proposal in the contemporaneity. We have taken as fundamental references the studies who do not consider the disability a stetic, natural, or definitive condition, since it is inserted in the relationships and interactions which determine its comprehension in the society. It is, therefore, a difference which emerges in the production process of people's existence at defined historical moments and places, as the ethnic differences, the linguistic codes, or the religious beliefs are in the same sense. In short, the diferenciation and the individuation which give substance to the human emancipation are still promises, for the individual who is different is someone socially denied, frequently pursued to be molded, included, and adapted.

Keywords: Difference; Discrimination; Disability

1 Professora Doutora da Universidade do Estado da Bahia - UNEB (Lauro de Freitas/Brasil). luciene@portfolium.com.br. 
A discussão sobre diferenças e diversidade na sociedade vem se constituindo em palavra de ordem na literatura educacional, motivada internacionalmente por documentos que apontam para a importância do princípio de "educação para todos". Muito tem sido enfatizado sobre a pedagogia da diferença voltada para a diversidade: respeito às diferenças, convívio com as diferenças, valor das diferenças, direito às diferenças são expressões valorizadas nas publicações mais recentes.

Embora a diferença seja um tema recorrente nas preocupações das ciências humanas, é possível identificar o destaque atualmente dado a essa temática por parte dos pesquisadores da área de educação. O interesse despertado parece ser devido aos conflitos contemporâneos marcados por elementos que a realçam, a exemplo do aumento populacional, os fluxos migratórios em direção às grandes cidades, a má distribuição de renda, a miscigenação de etnias, os sincretismos religiosos, os movimentos sociais por direitos humanos e a disponibilização de alguns serviços, ainda que tardia e lenta, para segmentos historicamente marginalizados, possibilitando mais visibilidade nos espaços públicos das áreas urbanas. Um dado a ser considerado é que os segmentos ditos diferenciados condicionam-se a uma história em que predominam relações e condições de existência extremamente desiguais, nas quais a propriedade é o que, principalmente, define o poder. Se a cultura não cumpriu sua promessa de conquista da liberdade é por estar ainda condicionada às suas tendências regressivas que impõem sacrifícios e levam a um estado de sobrevivência em que a vida deixa de ser um fim, tornando-se apenas uma possibilidade remota do que poderia vir a ser. Nesse âmbito, as relações sociais revelam a irracionalidade da cultura, que não permite a convivência com modos de ser diferenciados.

Este artigo apresenta uma discussão sobre diferenças, identificandoa como elemento de base para a reivindicação da escola inclusiva que propõe o atendimento de todos os alunos na escola regular independente das suas singularidades. Interessa-nos, mais particularmente, entender sobre o que faz as pessoas afirmarem tão freqüentemente a diferença, sem admiti-la nas suas relações cotidianas. Desenvolvo a análise a partir de três tópicos: o primeiro, uma discussão sobre os sentidos da diferença e o destaque dado pelas ciências humanas na atualidade; o segundo, sobre a deficiência como expressão de uma diferença, e por fim, abordo a deficiência como diferença negada. 


\section{SOCIEdAde E OS Múltiplos SENTIDOS DA DIFERENÇA}

Podemos afirmar que as ciências humanas vêm destacando sobremaneira a questão das diferenças, dentre as temáticas contemporâneas. Trata-se de evidenciar o processo que leva homens e mulheres à afirmação do igual e negação do diferente, dando um status negativo ou preconceituoso ao que consideram "o outro", "O estrangeiro", “o diferente". Esse "outro", porém, consiste em questão recorrente para a humanidade ao longo da história. A descrição da diversidade humana tem sido feita, principalmente, a partir de duas perspectivas: 1) a perspectiva etnocêntrica é a concepção dos que se empenham em transformar os valores próprios à sociedade a que pertencem em valores universais, julgando os costumes alheios a partir de analogias fundadas nos próprios costumes. Em conseqüência, o julgamento do outro informa mais sobre aqueles que falam do que sobre quem é falado, restringindo a amostragem do humano às culturas hegemônicas (TODOROV, 1993). Trata-se da desqualificação do "outro" em prol de um "mesmo" universal, tendo como premissa a existência de uma lógica predominante nos modos de percepção próprios da condição humana. Expressa o desejo de elaboração de uma teoria única do mundo, uma racionalidade capaz de atestar uma ampla gama de acontecimentos, inclusive, os particularismos; 2) já a perspectiva relativista proclama o valor igual para todas as diferenças, com privilégio para a descrição da coerência interna do grupo e do dinamismo criativo autônomo. Nessa perspectiva, a compreensão das experiências humanas parte da significação que têm no contexto em que se manifestam. Expressou um avanço do pensamento, na medida em que denunciou os ideais totalitários do etnocentrismo a exemplo da eugenia e do colonialismo. No entanto, a superação do etnocentrismo mostrou-se igualmente problemática e instaurou um dilema teórico e ético, pois, ao rejeitar pretensões universalistas, ainda assim, obriga-se a uma tradução da realidade já que a necessidade de compreensão dos valores do "outro" é um problema apenas para os que querem explicar e refletir sobre as configurações sociais. Ou seja, não deixa de ser também uma interpretação que traduz fatos. Nesse âmbito, mesmo entendendo que tais interpretações podem significar proteção às minorias, possibilitou também atestar movimentos de conservadores que buscam legitimar poderes em nome de uma diferença reivindicada.

As diferenças são definidas nos parâmetros da sociedade, visto que não existe diferença sem um grupo social já formado, que é o que lhe dá 
sentido. É o grupo que coletivamente conceitualiza uma diferença, que lhe dá importância e valor. A diferença é, portanto, socialmente formulada, na razão particular da existência dos grupos sociais que são definidos pelos tipos de interação e intensidade dos conflitos. Diante disso, é pertinente questionar sobre a possibilidade de o indivíduo se diferenciar perante uma realidade que o induz, cada vez mais, a moldar-se ao mundo da produção e à racionalidade tecnológica, condições essas adversas para a afirmação das diferenças e para a participação nos processos coletivos e/ou individuais. E mais: Qual o significado dessa diferença tão reivindicada atualmente e que se faz tão imperativa? Como objetivá-la de forma não enganosa, atribuindo um valor de afirmação das diferenças e valorização da igualdade?

A diferença vem se tornando quase que uma obsessão, com apelos explícitos ao individualismo e ao narcisismo, expressos por Sawaia (2001) como uma quase ditadura do "seja diferente, assegure sua identidade". Ao mesmo tempo, e paradoxalmente, essa formulação que apela para a afirmação dos indivíduos subsidia também os comportamentos xenófobos, na medida em que nomeia e identifica quem é quem, como vive, mapeando e controlando, para assim manter um equilíbrio de forças e, no limite, tornar esse outro diferente enquadrado nos padrões de diversidade necessária e, quiçá, mais um elemento exótico para ser mostrado como prova de tolerância social.

Pierucci (1999) apresenta questões instigantes na reflexão sobre diferenças, especialmente como pauta política. Para ele, a ideologia de direita consubstanciada no racismo ou no chauvinismo não é, em essência, "rejeição da diferença", mas o inverso, é a focalização ou obsessão por ela por meio de processos de controle que a naturaliza. Já os movimentos de esquerda a tomam como bandeira de luta, investindo num esforço discursivo para manter considerável distância dos argumentos conservadores. Nesse ponto, é possível constatar a imensa dificuldade que encontramos hoje para identificar os reais propósitos de programas de gestão e programas políticos e institucionais quando tratam de direitos das minorias ou suas manifestações culturais. Tudo passa a ser incrível e fantástico tornando-se moda e consumo para ser apreciado por pessoas diferentes, ainda que incorporando um visível deslocamento de intenções ou sugestões: quanto mais diferente melhor. Diz Pierucci (1999, p. 29):

Daí que essa atmosfera pós-moderna que hoje muitos de nós respiramos nos ambientes de esquerda, essa onda de celebração 
neo-barroca das diferenças, de apego às singularidades culturais, de apologia da irredutibilidade das particularidades e especificidades culturais, sociais e contextuais, tudo isso assusta muito pouco as cabeças de direita, também elas perpassadas de "fundamentalismo cultural" (ver Stolcke, 1993). Trata-se de um discurso absolutamente palatável, familiar mesmo, à direita popular. [...] Vale dizer que em nosso país o discurso não palatável e imediatamente odioso ainda é, cento e poucos anos depois da abolição da escravatura, o discurso abolicionista das desigualdades e subordinações, discriminações e humilhações, segregações e exclusões.

A contribuição do autor está na identificação das ciladas que a argumentação em favor das diferenças põe em destaque, da mesma forma que o discurso da igualdade, quando ele resvala para a homogeneização cultural. Cita um caso ocorrido nos Estados Unidos, em que uma entidade do governo, a Equal Employement Opportunities Commission (EEOC), moveu um processo contra a loja Sears, empresa varejista de roupas, alegando discriminação sexual em favor dos empregados de sexo masculino, na sua política de contratação para as seções que permite melhor remuneração por meio de vendas comissionadas. O processo chamou a atenção quando solicitaram como testemunhas de defesa e acusação duas intelectuais feministas para argumentar sobre questões de igualdade e diferenças. ${ }^{2}$ Nessa contenda, ganhou o argumento da diferença que favoreceu a Sears, desfavorecendo as mulheres trabalhadoras da empresa. Sob a alegação de que mulheres são diferentes de homens, bem como seus interesses, que são específicos e que devem ser respeitados, no caso, as funcionárias em questão "tinham objetivos e valores outros além do simples ganho econômico", dando a entender que a função das mulheres nos seus empregos diz respeito às suas atitudes e preferências, como seres diferentes fragilizando a argumentação igualitarista (PIERRUCCI, 1999, p. 39).

Conservadores sempre utilizaram o termo "diferença" para justificar relações de poder apelando para a ciência, natureza ou cultura. Dessa forma, as diversas manifestações de diferença, seja pela etnia, pelo gênero ou pelas características corporais e/ou sensoriais, são estruturadas sem correspondência com uma história de discriminação e preconceito que

2 As testemunhas foram as historiadoras Alice Kessler-Harris e Rosalins Rosemberg, feministas com vasta pesquisa e livros publicados sobre a temática. 
marcam as relações com os ditos diferentes. Por outro lado, o discurso crítico, se é que podemos chamá-lo assim, pode tornar-se equivocado quando destrói possibilidades de ação humana, por não perceberem que determinados posicionamentos dos indivíduos dão-se também devido às condições que os determinam. A celebração da diferença deve sair do discurso puramente apologético e fragmentário, identificando dezenas de "identidades" para proporcionar uma reflexão em favor de igualdade e justiça, base para o reconhecimento das diferenças individuais.

A nomeação da diferença no contexto de uma sociedade marcada pela exploração e segregação, cujas causas estão estreitamente relacionadas às relações de dominação, torna-se falsa, não aparecendo como diferença, mas como desigualdade. Ou, talvez, como um elemento exótico comprimido pela socialização, no seu aspecto mais regressivo que é a adaptação, dificultando progressivamente sua afirmação. Segundo Adorno (1986, p. 78):

As malhas do tecido social vão sendo atadas cada vez mais de acordo com o modelo do ato da troca. Permite à consciência individual cada vez menos espaço de manobra, passa a preformála de um modo cada vez mais radical, como que lhe cortando, $a$ priori, a possibilidade da diferença, que passa a se reduzir à mera nuance dentro da homogeneidade da oferta.

Sendo falsa, a diferença, tal como posta, é ideologia, ${ }^{2}$ é justificação, porque não convence da sua possibilidade nessa sociedade, na medida em que nega na prática o que ela tem de verdade, mostrando-a como mera diversidade das formas de vida e, por isso, factível para as relações harmoniosas. Sua defesa na atualidade não significa que a sociedade esteja num nível de consciência favorável à diferenciação e individuação, pois que continua, de forma intensiva, generalizando o primado da equivalência e do valor de troca. Esse aspecto inviabiliza a defesa dessa diferença como algo emancipador, mas como necessidade de identificação e mapeamento, para assim, melhor controlar e adaptar.

3 Ideologia, aqui entendida como em Adorno, a "consciência objetivamente necessária e, ao mesmo tempo, falsa, como interligação inseparável de verdade e inverdade, que se distingue, portanto, da verdade total tanto quanto da pura mentira..." (HORKHEIMER; ADORNO, 1973, p. 191). 


\section{A deficiência COMO difEREnçA}

A leitura social que é feita das diferenças tem resultado em atitudes, preconceitos, estereótipos e estigmatização que delegam à pessoa portadora de deficiência o lugar de cidadão de segunda categoria na sociedade. Segundo Goffman (1988, p. 11), estigma é um valor negativo atribuído a uma condição existencial e gerado na trama das relações sociais a partir do que é construído ideologicamente acerca do outro. Seu estudo sobre a manipulação de identidades deterioradas investigou diversos fatores ligados ao estigma, tais como a visibilidade, o encobertamento e a identidade pessoal, destacando que o termo "estigma" foi criado pelos gregos para identificar explicitamente por meio de sinais - cortes, marcas de fogo, tatuagem etc. - pessoas que evidenciavam comportamentos indesejáveis (traição, crime, homossexualismo), baixo status social (escravo, etnia, opção religiosa), ou deformidades físicas (cegueira, surdez, deficiência física). O autor prossegue dizendo, a respeito de estigma, que "o termo é amplamente usado de maneira um tanto semelhante ao sentido literal original, porém, é mais aplicado à própria desgraça do que à sua evidência corporal" (GOFFMAN, 1988, p. 13). Isso pode ser constatado em relação a algumas doenças, cujo significado remete à reprodução social do indivíduo e não apenas à sua sobrevivência biológica. Determinadas doenças, como câncer, hanseníase, sífilis, tuberculose e Aids, parecem ter uma relativa autonomia, tal a intensidade das suas representações e a persistência da depreciação dos adoecidos mesmo que não estejam com os sintomas mais intensos da doença. Historicamente, forjou-se uma estreita relação destas com o castigo divino, perda do controle de si ou ao destino de isolamento requerido para a cura ou sobrevivência do doente, que expressa mais sobre a articulação simbólica das identidades sociais do que propriamente a natureza das referidas doenças.

A sociedade marcada pela diversidade/multiplicidade das diferenças humanas - físicas, sociais, étnicas, econômicas, culturais, religiosas etc. incorpora também os indivíduos que não se encaixam nos chamados padrões de normalidade física ou mental, devido a causas acidentais ou congênitas que os tornaram pessoas com deficiências e enfrentam barreiras sociais diferenciadas, já que, em grande medida, o meio determina o efeito de uma deficiência ou de uma capacidade sobre a vida cotidiana de uma pessoa. Ela pode se perceber relegada à invalidez se the são negadas oportunidades necessárias aos aspectos fundamentais da vida, tais como trabalho, educação, habitação e lazer. 
Diversos autores (AMARAL, 1995; MAZZOTA, 1996; PAIXÃO, 1996) analisam a trajetória que expressa o significado da deficiência no processo histórico. A deficiência foi adquirindo variadas interpretações, desde sinal de forças ocultas da natureza até fatalidade orgânica que acomete os indivíduos, considerando necessidades emergentes que se põem na relação dos indivíduos com o meio. Sabe-se, pelos estudos realizados por diversas ciências (paleontologia, arqueologia, sociologia, história etc.), que as atitudes que mais predominam no decorrer da história da civilização em relação a esses indivíduos têm sido de abandono, exclusão, rejeição, discriminação ou preconceito.

No período de transição para a sociedade capitalista, as concepções sobrenaturais da deficiência dão lugar às explicações pautadas nos estudos de medicina da época, como um problema orgânico do indivíduo. No século XX, as experiências pedagógicas já realizadas por Pestalozzi (17461827), Froebel (1782-1852), Itard (1774-1838), Seguin (1812-1888), Maria Montessori (1870-1922), Decroly (1871-1922) possibilitaram o surgimento de propostas educacionais a pessoas com deficiência, que deram luz ao que hoje se denomina Educação Especial. Segundo Staimback et al. (1999, p. 38), "entre 1900 e 1930, disseminou-se generalizadamente a idéia de que as pessoas com deficiência tinham tendências criminosas e eram a mais séria ameaça à civilização, devido à sua composição genética”.

Esse caldo de cultura exerce influências até os dias atuais, e a demarcação das fronteiras da normalidade vem se constituindo, cada vez mais nitidamente, pelo mapa que expressa a acessibilidade dessas pessoas ao serviço de saúde, educação, lazer e trabalho. Mesmo com os avanços tecnológicos que já poderiam ter eliminado o trabalho repetitivo e o esforço físico, é o ideal do corpo útil que predomina, demandando um corpo rígido e funcional. Rejeita-se uma outra referência de corpo que admita a flexibilidade, a possibilidade e as particularidades. Além do corpo útil para o trabalho, valoriza-se também o corpo falsamente belo, porque padronizado em limites estéticos de peso, altura, cor e forma que favorecem a rejeição dos diferentes corpos fora dessas especificações.

A estética predominante tem um referente no qual o corpo se esgota em si mesmo. Desarticulado, desalinhado, são e produtivo, apesar de falso na sua essência, faz parte de uma idealização cujo afastamento caracteriza o desvio ou a anormalidade. A rejeição à diferença na nossa sociedade é um fenômeno que tem como referente o modelo jovem, masculino, cristão, heterossexual, produtivo, branco e fisicamente "perfeito". O corpo 
valorizado é o jovem e saudável, ainda que essas características sejam resultado de processos de intervenção (cirurgias, dietas, produtos cosméticos) que produzem a configuração corporal desejável na contemporaneidade. Seu grande sustentáculo é a hipervalorização estética, que sugere constantemente o corpo como sendo algo adaptável pela deliberação firme e enérgica da vontade pessoal. A mensagem é: você pode ter o corpo que deseja, basta acionar os recursos da ciência. Aliás, a saúde hoje tem o significado de boa forma física, entendida como o corpo "malhado" que expressa uma aversão a qualquer comprometimento do valor simbólico do corpo. A produção desse corpo dito saudável tem como expoente máximo uma poderosa indústria com grande visibilidade social por meio da proliferação de academias de ginásticas, terapias corporais e clínicas de cirurgia plástica. Esse corpo endurecido é um produto da história da cultura de dominação da natureza pelo homem, como afirma Crochik (1999, p. 14), "o que lembra a natureza dominada - a fragilidade, a imitação, o que não tem função, o que não tem controle - deve ser também dominado".

A referência de normalidade é, também, produto de um quantitativo social. A sociedade estabelece como um dos fatores essenciais para seu funcionamento e coesão a semelhança entre os indivíduos, fazendo surgir a norma a partir da ocorrência de uma infração que impõe uma série de reajustamentos diante da possibilidade da transgressão (TOMASINI, 1998). A norma é, portanto, um conjunto de traços definidores de um padrão que expressa o distanciamento entre os indivíduos, a partir da referência a um aspecto determinado. O que lhe dá significado é exatamente a presença e intensidade do diverso diante de tal referência, para assim posicionar e classificar o que é próximo ou estranho, regra ou desvio. E a tipificação da normalidade provoca uma fratura na seqüência de hábitos cotidianos acostumados com os padrões.

Dessa forma, não se pode negar que existe uma anormalidade historicamente construída, que tem como base a referência biológica e as respostas dadas nas relações com o meio, como esclarece Canguilhem (1995, p. 94): “O médico geralmente tira a norma do seu conhecimento de fisiologia, dita ciência do homem normal, de sua experiência vivida das funções orgânicas e da representação comum da norma num meio social, em dado momento." O autor demonstra a ambigüidade do termo "normal", na medida em que pode referir-se a um valor - o que é como deve ser, ou um fato - o que se encontra dentro da média. Os usos se 
confundem em circunstâncias semelhantes de emprego do termo "normal", à revelia da observância do significado por parte dos que o empregam. Argumenta que o uso primeiro do termo é o avaliativo, pois o descritivo (fato) informa quanto de afastamento da posição normal caracteriza o patológico. Entretanto, ainda que a medida utilizada para tanto seja científica, ela precisa recorrer a um valor, para assim avaliar a partir de que medida do afastamento do normal ingressamos no patológico. Esse aspecto é evidenciado por Carvalho (2004) como a construção social de uma oposição binária sobre as diferenças, em que "ser" e "não ser" são as únicas formas possíveis de estar no mundo, tornando-se normatizadores das classificações que desconsideram os aspectos socioculturais.

Amaral (1995) identifica três parâmetros sociais para a definição da "diferença significativa" ou deficiência como desvio ou anormalidade. O primeiro refere-se ao critério estatístico que impõe uma "média aritmética" dos valores sociais que predominam. Cita como exemplo a existência de uma altura média do homem brasileiro, assim como uma freqüência média de escolhas profissionais por gênero. $O$ segundo diz respeito às características da espécie humana, que tem na sua "vocação" genética uma forma e função, uma estrutura própria que a diferencia de outros seres; e, por último, o parâmetro que compara determinada pessoa com um tipo ideal construído pelo grupo dominante. Faz também uma distinção entre "deficiência primária" e "deficiência secundária", numa tentativa de expressar os fatores objetivos e subjetivos:

Entendo atualmente que "deficiência primária" engloba o impedimento (impairment) - dano ou anormalidade de estrutura ou função: o olho lesado, o braço paralisado, a perna inexistente... e a deficiência propriamente dita (disability) - restrição/perda de atividade, seqüela: o não ver, o não manipular, o não andar... Referese portanto aos fatores intrínsecos, às limitações em si. À pessoa/ corpo. [...] "Deficiência secundária" está ligada ao conceito de incapacidade (bandicap) e, em decorrência, de desvantagem. [...] Ou seja, deficiência secundária é aquela não inerente necessariamente à diferença em si, mas ligada também à leitura social que é feita dessa diferença. (AMARAL, 1994, p. 17)

Já Omote (1994, p. 66) rejeita a descrição das deficiências fora de uma linguagem de relações. Para ele, a diferença em si deixa de existir, torna-se abstrata, posto que um atributo particular passa a ter sentido de "vantagem ou desvantagem dependendo de quem é o portador ou o ator 
e de quem são os seus 'outros', isto é, a sua audiência, assim como outros fatores circunstanciais definidos pelo contexto no qual ocorre o encontro". Fica claro que o conceito de deficiência condiciona-se às instâncias valorativas do contexto social que o significa e esse sentido é dado não como uma simples caracterização classificatória do sistema de valores de uma dada sociedade, mas, principalmente, como uma atitude de cunho político, que, além de prescrever encaminhamentos para orientações práticas, causam expectativas sociais em relação às pessoas com deficiência.

Para Diniz (2003, p. 1), o conceito de deficiência não pode considerar apenas os aspectos de lesão, perdas ou alterações orgânicas, cabendo enfatizar também os aspectos sociais que a tornam um fenômeno de subalternidade. Sua definição para deficiência é:

Deve-se entender deficiência como um conceito amplo e relacional. É deficiência toda e qualquer forma de desvantagem resultante da relação do corpo com lesões e a sociedade. Lesão, por sua vez, engloba doenças crônicas, desvios ou traumas que, na relação com o meio ambiente, implica em restrições de habilidades consideradas comuns às pessoas com mesma idade e sexo em cada sociedade. Lembro que deficiência é um conceito aplicado a situações de saúde e doença e, em alguma medida, é relativo às sociedades onde as pessoas deficientes vivem.

Nesse sentido, a deficiência não é uma condição estática, natural e definitiva, ela está inscrita nas relações e interações que determinam seu entendimento na sociedade. É, portanto, uma diferença que emerge no processo de produção da existência dos povos, em locais e momentos históricos distintos, assim como são, nesse sentido, as diferenças étnicas, os códigos lingüísticos ou as crenças religiosas. A condição de deficiência evidencia uma situação de desvantagem só compreensível numa situação relacional ou em consideração a um outro: desvantagens, incapacidades ou deficiências são consideradas sempre na relação do indivíduo portador de tais características com os seus pares de convivência. Mas a palavra deficiência por si só já se opõe à eficiência, princípio caro para a sociedade capitalista moderna cuja preocupação maior é a produtividade. E a lógica do capital não admite a suposta desordem do corpo ou dos sentidos: um corpo fora de ordem, anormal, inviabiliza a racionalidade técnica, evidenciando, dessa forma, uma contradição dada por sua conversão em (ir)racionalidade da dominação. 
Nos EUA e Europa, a discussão sobre deficiências conta com um campo teórico específico denominado Disability Studies. Segundo Diniz (2003), esses estudos têm expressão nas universidades britânicas, consolidado como campo de pesquisa que agrega as ciências humanas, sobretudo a sociologia, e as ciências da saúde, abordando questões sociais, éticas, estéticas e políticas. Também nos Estados Unidos encontram-se, em diversos departamentos universitários (University Illinois at Chicago, University of North Carolina), núcleos de Disability Studies, que podem ser caracterizados como um campo de estudos que examina a história, a literatura e a sociologia, da mesma forma como os Estudos Culturais, Estudos Étnicos ou Estudos sobre Gênero as observam para analisar os temas relativos aos hispânicos, negros e mulheres, entre outros. Os estudiosos desse campo sociológico, que surgiu na década de 1970, alinham-se aos movimentos de direitos humanos, os Disability Right Movements, tendo participação intensa de pessoas com deficiência. É possível identificar, em programas de pós-graduação, eixos temáticos para essa área de estudos assim discriminados: Disability and Culture (como as deficiências são compreendidas nas diversas culturas, como se constituem enquanto cultura minoritária); The History of Disability (principais fatos que influenciam os movimentos dos direitos humanos e como eles iluminam as pesquisas contemporâneas); Basic Concepts in Research Methodology in Disability Research (revisão sobre conceitos importantes na literatura sobre deficiência para o desenvolvimento de pesquisa).

Foi no âmbito dos Disability Rights Movements, sobretudo na Inglaterra, que surgiram as denominações Modelo Médico da Deficiência para a descrição clínica ou biológica que explica a deficiência como lesão ou desvio da normalidade, falta ou déficit, ignorando o peso das estruturas sociais, prescrevendo a "cura" por meio de reabilitação e medicalização, e o Modelo Social da Deficiência com um outro tipo de explicação causal em que se priorizam os aspectos externos e impeditivos para a realização da independência das pessoas com deficiência. Ou seja, sua interpretação é calcada no contexto da sociedade e na condição favorecedora ou não da adaptação: existência de barreiras arquitetônicas, vagas para emprego, direitos civis garantidos, inclusão nas escolas e sistemas de saúde. Percebese que a causa é deslocada da lesão para seus aspectos externos, que constituem as barreiras sociais, com uma argumentação neutralizadora da disfunção orgânica e, assim, politizando o enfrentamento da deficiência, propondo ações e atitudes sociais afirmativas. De forma semelhante ao 
movimento feminista ou ao movimento negro, por exemplo, quando para desnaturalizar o atributo de ser mulher ou ser negro, passou a posicionálo como tensão em relação à cultura, retirando da natureza a justificativa para a dependência. Com isso, lesão e deficiência foram desagregados, indicando que a última é um fenômeno sociológico determinado pelas barreiras sociais restritivas. Já a lesão é um fenômeno biológico:

Lesão para o Modelo Social da Deficiência é o equivalente nos estudos de gênero, a sexo. E assim como o papel de gênero que cabe a cada sexo é resultado da socialização, a significação da lesão como deficiência é um processo estritamente social. Nesta linha de raciocínio, a explicação para o baixo nível educacional ou para o desemprego de um deficiente não deveriam ser buscadas nas restrições provocadas pela lesão, mas nas barreiras sociais que limitam a expressão de suas capacidades. (DINIZ, 2003, p. 2)

Com esse entendimento, a superação da condição de fragilidade social das pessoas com deficiências deve ser viabilizada por meio de ações políticas e não simplesmente terapêuticas, retirando do indivíduo a responsabilidade pela sua posição na sociedade, sem com isso negar os avanços da medicina para o conforto das pessoas com deficiência, resistindo, porém, à pura medicalização pela cura, processo que consolidou-se com a contribuição da área de educação. Essa discussão intensificou-se a tal ponto, principalmente nos Estados Unidos e na Inglaterra, com o envolvimento de estudiosos e acadêmicos bem como com o "movimento de deficientes", que resultou na revisão da Classificação Internacional de Funcionalidade, Incapacidade e Saúde pela Organização Mundial da Saúde (OMS) em 2001, depois de acirradas discussões da versão anterior do documento, que ainda admitia princípios causais de lesão, deficiência e restrição, classificando, de fato, as conseqüências das doenças. ${ }^{4}$ Os princípios considerados atualmente nessa classificação internacionalmente padronizada são os de

$4 \quad 0$ International Classification of Functioning, Disability and Health, também conhecido como CIF, é uma espécie de catálogo que unifica e padroniza o sistema de descrições dos estados de saúde. Os dados relativos à população com deficiência do último censo do IBGE foram questionados, porque foram considerados exacerbados, ultrapassando os percentuais previstos até então pela OMS para países em desenvolvimento. Para Medeiros, pesquisador do Instituto de Pesquisas Econômicas Aplicadas (IPEA), os dados revelam que o parâmetro utilizado para identificação das deficiências - não como defeitos clínicos, ampliando o conceito de deficiência - já é reflexo da tendência atual de não desarticular lesão de dificuldade, tal como orienta o catálogo. 
funcionamento e de capacidade, ou seja, qualquer limitação do corpo pode ser classificada como deficiência baseando-se na relação existente entre corpo e sociedade:

Os domínios contidos na CIF podem, portanto, ser considerados como domínios da saúde e domínios relacionados à saúde. Esses domínios são descritos com base na perspectiva do corpo, do indivíduo e da sociedade em duas listas básicas: (1) Funções e Estruturas do Corpo, e (2) Atividades e Participação. Como uma classificação, a CIF agrupa sistematicamente diferentes domínios de uma pessoa em um determinado estado de saúde (e.g. o que uma pessoa com uma doença ou transtorno faz ou pode fazer). Funcionalidade é um termo que abrange todas as funções do corpo, atividades e participação; de maneira similar, incapacidade é um termo que abrange incapacidades, limitação de atividades ou restrição na participação. A CIF também relaciona os fatores ambientais que interagem com todos estes construtos. Neste sentido, ela permite ao usuário registrar perfis úteis da funcionalidade, incapacidade e saúde dos indivíduos em vários domínios (CENTRO BRASILEIRO DE CLASSIFICAÇÃO DE DOENÇAS, 2004).

O catálogo deixou de ser um documento de classificação das "conseqüências das doenças" para ser uma classificação sobre os "componentes da saúde". O conceito de deficiência passa a ser uma classificação neutra frente à diversidade corporal humana e não mais um destino da natureza imposto pela lesão. (DINIZ, 2003, p. 3)

Dessa forma, o conceito de deficiência não mais deve ser a expressão referida aos resultados da doença, indicando um desígnio imposto por uma lesão. Ademais, as estratégias de prevenção, reabilitação e/ ou inclusão não são mais aspirações, são possibilidades concretas, dada a evolução das ciências, porém, a configuração da sociedade impede a viabilização dessas medidas para todos. Vemos hoje não apenas a promessa de cura para as aflições do corpo como também o campo da medicina genética aprimorando técnicas para inviabilizar a manifestação de doenças ou deficiências ainda na fase pré-embrionária. Mais que isso, o Projeto Genoma Humano ${ }^{5}$ é um investimento da ciência por parte de vários países,

5 Trata-se, conforme Rose (1997, p. 18), de um projeto que tem um custo de 3 bilhões de dólares com o objetivo de "mapear e seqüenciar todo o alfabeto de DNA dos cromossomos humanos". O autor, embora concorde que o aumento dos conhecimentos neuro-científicos 
inclusive o Brasil, para deter conhecimentos sobre o DNA, buscando evitar as predisposições genéticas de doenças. Algo como um controle do vir-aser, uma cura prévia do ser humano, porque antes mesmo de qualquer diagnóstico. São consideradas práticas preditivas e, quiçá, eugênicas, por pretender corrigir eventuais "defeitos" do corpo que existem apenas em potencial, rendendo um debate acalorado em torno de questões políticas e éticas. ${ }^{6}$

Uma questão polêmica que vem sendo bastante discutida, desde a década de 1980, diz respeito à interrupção seletiva da gestação que pode ser também relacionada à atitude preconceituosa. ${ }^{7} \mathrm{O}$ aborto seletivo, como vem sendo denominado, remete a um debate acerca da moralidade de tal ato que se expressa em dois argumentos antagônicos: a) o posicionamento em sua defesa como prevenção da deficiência, tal como é a vacinação ou qualquer tratamento para superação de uma limitação sensorial ou mental; b) a crítica a esse argumento por estar afirmando valores negativos associados à deficiência. Segundo Barros (2005, p. 91):

A discriminação expressada seria colocada em termos de uma mensagem, supostamente e subliminarmente dirigida aos deficientes, que informaria o caráter indesejado de suas presenças. Algo que equivaleria ao julgamento de que as vidas das pessoas deficientes são menos dignas de serem vividas do que as das pessoas que não têm deficiências. Tal sugestão, emitida a partir da condição de deficiente dos fetos e daí dirigida a todos os deficientes vivos, de

irão reduzir o sofrimento humano, questiona a forma de aplicabilidade desses novos conhecimentos diante do modelo reducionista e determinista que ainda prevalece na ciência aplicada.

6 A eugenia é um movimento com pretensões de melhorar ou aprimorar a espécie humana através de recursos variados, de métodos higienistas, moralistas e de manipulação genética que teve nuanças diferenciadas nos diversos países. Em análise realizada sobre o movimento eugenista no Brasil no período de 1917-1940, Stepan (1990) identifica uma conformação ideológica adaptada à "topografia intelectual" brasileira que focalizou mais as políticas sociais de modernização e assepsia por meio de ações no campo de saúde pública e saneamento ambiental, diferentemente da sociedade estadunidense, que investiu na ideologia racial segregacionista e assimilacionista, e a alemã, com a radicalização disso em busca da raça pura.

7 Segundo Diniz (2003, p. 2), existem quatro tipos de situação de aborto: a interrupção eugênica da gestação a partir de argumentos racistas, sexistas, étnicos etc.; a interrupção terapêutica da gestação, em função da saúde materna, no sentido de salvar a vida da gestante; a interrupção seletiva da gestação ou aborto ocorrido devido ao diagnóstico de anomalias fetais; e a interrupção voluntária da gestação que se dá em nome da autonomia da gestante que não deseja a gravidez. Dessas, apenas a primeira não leva em consideração a vontade da mãe para manter a gestação. 
que a própria existência dessas pessoas com deficiência não deveria ser permitida ou valorizada.

Diversas outras técnicas consideradas preditivas, que abrangem, desde diagnóstico pré-natal até a fertilização in vitro com reprodução assistida, têm sido disseminadas para casais que pretendem ter filhos e que podem pagar caro, dado o alto custo do tratamento que envolve a realização de diversos exames laboratoriais e clínicos. Entretanto, muito dos casos de deficiência poderiam ser evitados se houvesse uma política de saúde pública atenta para questões preventivas de baixo custo como aconselhamento genético, orientação sobre os riscos de gravidez em mulheres com mais de 35 anos, vacinação contra rubéola, complementação de vitaminas e ácido fólico, exames pré-natal e durante a gravidez, acompanhamento médico e testes nos bebês (teste do "pezinho" e teste da "orelhinha"). Isso é corroborado pelas estimativas da OMS para as circunstâncias que poderiam evitar as deficiências:

No panorama mundial mapeado em 1995, destacam-se como evitáveis os transtornos congênitos e perinatais, que muitas vezes ocorrem em conseqüência da falta de exame pré-natal (16,6\%); as enfermidades transmissíveis $(16,8 \%)$; as enfermidades crônicodegenerativas $(21 \%)$ e a desnutrição (11\%); além das alterações de ordem psicológica $(6,6 \%)$ e do alcoolismo e do abuso de drogas $(10 \%)$. A esses fatores, somam-se ainda as causas externas, como os diversos tipos de acidentes (18\%). (VIVARTA, 2003, p. 116)

Embora o universo das deficiências seja bastante amplo, com especificidades, às vezes, extremamente diferenciadas a depender da variável que se seleciona, entendemos que existe uma limitação que é real e que, no âmbito das relações sociais desumanizadas, traduz-se em preconceito. A pessoa com deficiência passa a ser não eficiente para fins diversos, um ser inadaptado aos padrões considerados normais na sociedade. O conjunto de normas e regras que a sociedade elabora configura-se, dessa forma, em restrições no sentido de garantir uma convivência em conformação com tais critérios. Essa é uma discussão fértil em autores como Bueno (1997), Amaral (1995) e Omote (1994), que enfatizam o caráter relacional entre as representações da deficiência e o meio cultural. As classificações das pessoas na categoria de deficientes sempre se mostram como um risco de reduzi-los a sujeitos do déficit, não pela observação de uma limitação real, mas pela possibilidade de imputar- 
lhes valores formados socialmente e, dessa forma, apontar dificuldades como se fossem inerentes à sua própria individualidade. A deficiência, ao se tornar um problema do indivíduo, vai forçá-lo à adaptação, à busca por integrar-se, muitas vezes, contra a sua vontade, comportando-se docilmente, submetendo-se ao autoritarismo travestido de prática generosa.

\section{A DEFICIÊnCIA COMO DIFERENÇA NEGADA}

A discussão sobre as deficiências como diferença negada, decerto impulsionadora da luta pelos direitos das pessoas com deficiências, deixou à margem outros pontos que dizem respeito à subjetividade, tal como aconteceu também com outros movimentos de minorias, em que se acreditou serem as estruturas sociais rígidas e opressoras o único ponto a ser denunciado e combatido sem atentar para outras tantas questões internas nessa abordagem. Algo como uma mensagem: uma vez transformada a estrutura da sociedade teremos, de imediato, relações de igualdade, pois a questão é puramente política. É possível identificar nas discussões e nos estudos um peso ou um destaque dado à questão do "trabalho como direito humano fundamental", entendendo-o como a chave da independência das pessoas com deficiência. Na verdade, bandeiras políticas como essa não são totalmente adequadas para qualquer perfil de deficiência, tornando-se um ideal perverso para aqueles que têm lesões graves. Nesses casos, a proposição humanista e educativa deve ser pelo princípio de bem-estar e de "interdependência" que levam em consideração as necessidades especiais do corpo lesado e comprometido. Mesmo o trabalho não pode ser tomado como critério afirmativo de hombridade, numa sociedade com relações sociais marcadamente assimétricas. Outras questões também importantes têm sido indicadas pelo movimento feminista, principalmente, no campo da subjetividade: o significado da experiência da dor e do corpo lesado e sua simultaneidade para as atividades diárias, o alargamento do conceito de deficiência incorporando a condição de envelhecimento e doenças crônicas, a condição de mulher com deficiência, entre outras.

A complexidade dessas discussões revela que homogeneização e diversificação são movimentos que se processam com tensão e conflito. Vemos hoje algumas manifestações por parte dos "diferentes", que podem ser consideradas inusitadas, causando estranheza sobre as suas demandas, desafiando os mecanismos de controle e mesmo os limites normativos que se impõem como parâmetro do normal ou patológico. Segundo Diniz 
(2003), comunidades surdas das sociedades americana e inglesa têm reivindicado a união matrimonial entre pessoas surdas, para possibilitar o nascimento de filhos com a mesma deficiência e, assim, uma melhor qualidade de vida para a família, ou ainda, para os que podem seguir as prescrições dos aconselhamentos genéticos, escolher embriões surdos em detrimento de embriões ouvintes, por meio das tecnologias reprodutivas, provocando um conflito na questão da soberania da autonomia reprodutiva das pessoas:

Diferente do passado, quando famílias de surdos eram arbitrariamente esterilizadas ou mesmo crianças surdas eram transformadas em cobaias de pesquisa, os dilemas atuais impostos pela genética clínica são de outra ordem. [...] O avanço nas técnicas de mapeamento genético, além da segurança de diagnóstico, tornou possível algo considerado impensável há algumas décadas: a possibilidade de a comunidade surda afirmar, por meio da ciência, a preferência pelo surdo. (DINIZ, 2003, p. 176)

Numa direção aparentemente contrária, Souza e Gallo (2002, p. 40) relatam:

No dia 3 de abril de 2002, os senadores aprovaram a emenda da Câmara relativa ao projeto de Benedita da Silva, reconhecendo como meio legal de comunicação e expressão de comunidades surdas do país a Língua Brasileira de Sinais (libras). No dia 11 de abril, circulou na Internet um abaixo-assinado, destinado àqueles senadores, elaborado por um grupo de surdos autodenominados "surdos oralizados", que insistiam na idéia de que "somente a oralização amplia nossas capacidades e iniciativas como qualquer ser humano" e, por isso, enfatizavam "que somente o oralismo é capaz de, como um todo, nos incluir na sociedade". Os autores do abaixo-assinado compararam a libras ao latim, metáfora que ativa a memória de língua morta, sistema sem território de inscrição e sem usuários vivos.

Esses dados fazem ver que reivindicações em relação aos direitos não se restringem às representações hegemônicas do que se pensa ser uma humanidade constituída e natural, pois as diferenças, assim como a identidade, mesmo num contexto de dissolução do sujeito, são atravessadas por subjetividades diversas, não são totalidades fixas e estáticas passíveis de atribuição sem conflitos sobre a legitimidade dos modos de ser. Nesse 
sentido, a relação com o diferente não se constitui como harmonia simétrica capaz de anular todas as especificidades dos indivíduos.

Vivemos numa sociedade onde tudo se transforma em produtos de consumo, e, embora sejam oferecidos com um amplo cartel de opções ao "gosto do freguês", existe uma base valorativa, estética e funcional que padroniza o olhar. Mesmo as relações sociais seguem esse esquema, na medida em que a socialização possível boicota os contatos e as experiências, permitindo, não raro, interações superficiais amalgamadas por necessidades produzidas no âmbito da indústria cultural. E a ideologia está atualmente tão colada à realidade, no sentido de que já não é mais a sua máscara encobridora, que a transforma na sua verdade falsificadora, levando-nos à percepção de que temos uma sociedade mais heterogênea, quando na realidade ela está mais estruturada e mais previsível. Quanto a isso, Horkheimer e Adorno (1973, p. 202) são esclarecedores:

A rigidez inexperiente do mecanismo de pensamento que domina a sociedade de massa torna-se ainda mais inflexível, se isso é possível, e a própria ideologia impede que se desmascare o produto oferecido, em sua qualidade de objeto premeditado para fins de controle social, em virtude de um certeiro pseudo-realismo que, sob o aspecto da exterioridade, proporciona uma imagem permanentemente exata e fiel da realidade empírica.

A pseudoformação é determinante para a legitimação dessa realidade. É ela que veicula seus postulados, os mesmos que limitam o processo de constituição dos indivíduos: a divisão social do trabalho que impõe a dicotomia trabalho manual/trabalho intelectual, o reforço do individualismo e a desigual distribuição de renda. $\mathrm{Na}$ base da socialização totalitária, em que predomina o movimento pela padronização e indiferenciação, está a irracionalidade das formas de organização social baseada em relações cuja essência é contrária à emancipação.

Dessa forma, a diferenciação e individuação, que dão substância à emancipação humana, são apenas promessas, pois o indivíduo que se diferencia é um outro negado socialmente, freqüentemente perseguido para ser moldado, incluído e adaptado. Quanto a isso, Horkheimer e Adorno (1973, p. 39) afirmam: “O que parece estar 'de fora' mantém-se nessa sua extraterritorialidade, mais como algo que é tolerado ou que se situa num plano mais amplo, do que em virtude de uma autêntica e indiscutível manutenção do 'exótico.". 
A educação escolar tem sido um veículo de legitimação de segregação, pois conta com um saber que se presta à correção e controle, intensificando a estigmatização e discriminação. Esse saber é tomado como suficiente para se lidar com as pessoas com deficiência. O risco que existe nas classificações e categorizações dos alunos com deficiência está exatamente no fato de que, ao olhar especificamente para a patologia, se atribui qualquer dificuldade ou insucesso na escola a ela, quando o problema pode estar na escola, e isso não diz respeito apenas aos alunos com deficiência. Sabemos que a instituição escolar é o local onde circulam hierarquias e valores nas suas formas evidentes e ocultas, expressando as contradições e conflitos da sociedade, entretanto, seu cotidiano didático/ pedagógico permanece ignorando a diversidade do alunado. Em relação aos alunos com deficiência, é preciso considerar a existência de fatores geradores da situação de marginalização em que se encontram. A história da educação especial é um dos elementos que elucida uma parte considerável dessa situação. Também o encaminhamento dado pelas instituições especializadas nem sempre colabora para reverter as representações sobre a particularidade da deficiência como diferença, permitindo que um outro fale pelas pessoas com deficiência, e o discurso que se destaca é o que fomenta a condição de doença e de anormalidade das abordagens médicas e/ou psicológicas, constituindo, assim, a divisão entre eficientes e deficientes, capazes e incapazes, princípio bastante conveniente para o mercado de trabalho voltado à máxima produtividade. Entretanto, a base produtiva na sociedade contemporânea não está, principalmente, no esforço físico dos trabalhadores, mas no funcionamento de máquinas e manipulação de informações produzidas pelas novas tecnologias, facilitando cada vez mais sua operação, tornando insuficiente a argumentação de que habilidades manuais e destrezas do corpo são as condições exclusivas para o trabalho. Dessa forma, em se tratando das pessoas com deficiência física, as limitações motoras necessariamente não os impossibilitam para o exercício do trabalho, sendo, pois, as relações sociais, tais como se apresentam, o fator determinante para a não incorporação das pessoas com deficiência no mundo do trabalho.

Os encaminhamentos dados pelas políticas públicas e as propostas dos movimentos sociais para tornar possível a participação das pessoas com deficiência na sociedade apelam para argumentos de "reparação" ou de reflexão sobre os condicionantes que prescrevem a esses indivíduos um lugar inferiorizado, marcado pela dependência e discriminação. As 
políticas afirmativas recorrem a medidas para compensar e/ou reparar perdas em razão de abuso ou de prejuízos acumulados no passado. São as propostas de cotas para empregos ${ }^{8}$ e, mais recentemente, também para vagas na Universidade, ou a concessão de benefício em forma de salário para pessoas com deficiências de qualquer faixa etária. ${ }^{9}$ As políticas compensatórias constituem-se de ações afirmativas que visam corrigir discriminações históricas contra os grupos socialmente mais vulneráveis. A Constituição Brasileira dispõe de duas leis voltadas para acessibilidade das pessoas com deficiência no mercado de trabalho. ${ }^{10}$ Trata-se de uma estratégia considerada politicamente correta, visando corrigir distorções históricas, que, sem políticas afirmativas, permanecerão ainda por muitas gerações perpetuando a mesma situação de desigualdade e injustiça.

A reflexão sobre os condicionantes estruturais denuncia as condições de estigmatização de que são vítimas as pessoas com deficiência em função da dinâmica do processo sócio-histórico. Observamos que essa importante reflexão vem acompanhando a maioria dos estudos sobre a escola inclusiva, que vai num movimento inverso como proposta inconciliável com escolas ou classes especiais segregadas e com clara disposição de mudança no funcionamento da escola, como uma expressão de democratização do ensino. Porém, sem o reconhecimento de que tal proposta é "parte do ideário liberal" que reclama direitos iguais para todos, postulado formal da sociedade democrática, corre-se o risco de abortar uma possibilidade de ação educacional cujos procedimentos questionam a segregação de alunos em instituições especiais e busca olhar a diversidade no grupo de alunos e não no aluno com deficiência. Se, por um lado, ela não visa transformações da base social, pode servir para revelar a violência inerente nas relações sociais deterioradas que determina a desumanização e se traduz em preconceito e segregação (CROCHIK, 2002). Se, como dissemos antes, ainda não possuímos as condições para o livre exercício

8 Previsto pelo Decreto n. 3.298 de 20 de dezembro de 1999, que obriga as empresas que tenham 100 ou mais empregados a preencher de $2 \%$ a $5 \%$ de seus cargos funcionais com pessoas que apresentem deficiências.

9 Denominado "Benefício de prestação continuada", no valor de 1 salário mínimo para as pessoas com deficiência que comprovem não ter condições econômicas para sua manutenção.

10 A Lei n. 8.212, de 11 de dezembro de 1990, prevê reserva de vagas para pessoas com deficiência em concursos públicos e a Lei Federal n. 8.213, de 15 de julho de 1991 prevê que empresas com mais de 100 empregados devem reservar de $2 \%$ a $5 \%$ de seus cargos para pessoas com deficiência física, mental, sensorial ou múltipla habilitadas. 
da individuação e afirmação da diferença, pois que a base da discriminação não foi desestabilizada, cabe enfatizar e defender a emancipação, a autonomia e a diferenciação como possíveis aos seres humanos; entendêlos como indivíduos capazes de dar sentido, pela reflexão elaborada, às situações e interações no mundo em que vivem.

\section{Referências}

ADORNO, T. W. Crítica cultural e sociedade. In: COHN, Gabriel (Org.). Theodor W. Adorno. São Paulo: Ática, 1986.

AMARAL, Lígia Assunção. Pensar a diferença/ deficiência. Brasília: CORDE, 1994. Conhecendo a deficiência (em companbia de Hércules). São Paulo: Robe Editorial, 1995.

BARROS, Alessandra. A deficiência relativizada: entre discursos e a prática política. 2005. 184 f. Tese (Doutorado em Ciências Sociais) - Faculdade de Filosofia e Ciências Humanas, Universidade Federal da Bahia, Salvador, 2005.

BUENO, José Geraldo da Silveira. A produção social da identidade do anormal. In: FREITAS, Marcos C. de. (Org.). História social da infância no Brasil. São Paulo: Cortez, 1997.

CANGUILHEM, Georges. O normal e patológico. Rio de Janeiro: Forense Universitária, 1995.

CARVALHO, Rosita Edler. Educação inclusiva com os pingos nos "is". Porto Alegre: Mediação, 2004.

CENTRO BRASILEIRO DE CLASSIFICAÇÃO DE DOENÇAS. Classificação Internacional de Funcionalidades, Incapacidades e Saúde. Disponível em: < http://hygeia.fsp.usp.br/cbcd/cifWeb.htm>. Acesso em: 25 mar. 2004.

CROCHIK, José Leon. A ideologia da racionalidade tecnológica e apersonalidade narcisista. 1999. 280 f. Tese (Livre Docência em Psicologia) - Instituto de Psicologia, Universidade de São Paulo, São Paulo, 1999.

Apontamentos sobre a educação inclusiva. In: SANTOS, Gislene A.; SILVA, Divino Jose (Org.). Estudos sobre ética: a construção de valores na sociedade e na educação. São Paulo: Casa do Psicólogo, 2002.

DINIZ, Débora. Modelo social da deficiência: a crítica feminista. Brasilia: Letras Livres, 2003. (Série Aniz, 28).

GOFFMAN, Erving. Estigma. Notas sobre a manipulação da identidade deteriorada. Rio de Janeiro: LTC Editora, 1988.

HORKHEIMER, M.; ADORNO, T. W. Temas básicos de Sociologia. São Paulo: Cultrix, 1973. (Cap. 2, 3, 5 e 7). 
MAZZOTTA, Marcos J. S. Educação Especial no Brasil: história e políticas públicas. São Paulo: Cortez, 1996.

OMOTE, Sadao. Deficiência e não-deficiência: recortes de um mesmo tecido. Revista Brasileira de Educação Especial, Piracicaba, v. 1, n. 2, p. 65-73, 1994.

PAIXÃO, Adriana Gomes. As representações sociais e a deficiência: entre o estigma e a transcendência. 1996. 190 f. Dissertação (Mestrado em Educação) - Departamento de Educação, Pontifícia Universidade Católica, Rio de Janeiro, 1996.

PIERUCCI, Antonio Flávio. Ciladas da diferença. São Paulo: USP, 1999.

ROSE, Steven. A perturbadora ascensão do determinismo neurogenético. Ciência Hoje, Rio de Janeiro, v. 21, n. 126, p. 18-27, jan./fev. 1997.

SAWAIA, Bader. Identidade - uma ideologia separatista? In: SAWAIA, Bader. As artimanhas da exclusão: análise psicossocial e ética da desigualdade social. Rio de Janeiro: Vozes, 2001.

SOUZA, Regina M.; GALLO, Silvio. Por que matamos o barbeiro? Reflexões preliminares sobre a paradoxal exclusão do outro. Educação e Sociedade, Campinas, v. 23, n. 79, ano 23, p. 39-63, ago. 2002.

STAIMBACK, Susan; STAIMBACK, W. Inclusão: um guia para educadores. Porto Alegre: Artes Médicas, 1999.

STEPAN, N. L. Eugenics in Brasil 1917-1940. In: ADAMS, M. A. The Wellborn science: eugenics in Germany, France, Brazil and Russia. New York: Oxford University Press, 1990.

TODOROV, Tzvetan. Nós e os outros: a reflexão francesa sobre a diversidade humana. Rio de Janeiro: Jorge Zahar, 1993.

TOMASINI, Maria Elisabete Archer. Expatriação social e a segregação institucional da diferença: reflexões. In: BIANCHETTI, L.; FREIRE, Ida Mara (Org.). Um olhar sobre a diferença: interação, trabalho e cidadania. Campinas: Papirus, 1998.

VIVARTA, Vert. Mídia e deficiência. Brasília: ANDI, Fundação Banco do Brasil, 2003.

Recebido em: 16/11/2005

Aprovado em: 18/07/2006 